NASZA DERMATOLOGIA Online OUR DERMATOLOGY Online

Source of Support: Nil

Competing Interests: None

\section{AMOXICILLIN AND CLAVULANATE POTASSIUM RELATED LEUCOCYTOCLASTIC VASCULITIS}

\author{
Snehal Balvant Lunge, Vijaya V. Sajjan, Ashok M. Pandit, \\ B.S. Manjunathswamy, Shivakumar Patil, Anshul Agrawal \\ Department of Dermatology, Jawaharlal Nehru Medical College, Belgaum, India \\ Corresponding author: Ass. Prof. Snehal Balvant Lunge \\ drsnehallunge@gmail.com
}

\begin{abstract}
Leukocytoclastic vasculitis (LCV) is a small-vessel vasculitis with a reported incidence rate of 30 cases per million persons per year. It usually presents as a palpable purpuric skin rash on legs, though any part of the body can be affected. LCV rash may have an associated burning sensation or pain and in some cases may involve internal organs. In some cases, LCV rash may present as nodules, recurrent ulcerations or asymptomatic lesions. The diagnosis of LCV is usually made on skin biopsy. Etiological triggers may not be identified in as many as half of the cases. Treatment is usually conservative and includes identification and removal or treatment of the etiological trigger except in cases with internal organ involvement where systemic steroids and immunosuppressant may be necessary. In this article we present a case of Amoxicillin and Clavulanate potassium associated LCV that improved with discontinuation of the offending agent and treatment with systemic corticosteroids.
\end{abstract}

Key words: Amoxicillin and Clavulanate potassium; Leukocytoclastic vasculitis, perivascular and vascular leucocytic infiltrates

\section{Introduction}

Leukocytoclastic vasculitis (LCV) (hypersensitivity vasculitis) is a term commonly used to denote a small-vessel vasculitis. Many possible causes or associations have been proposed for LCV, but a cause or an associated disorder may not be found in as many as half of the cases.

LCV presents clinically as a cutaneous disease with or without internal body organ involvement. The prognosis of LCV is usually good if internal organs are not affected. The internal organs most commonly involved in LCV are the joints, gastrointestinal tract, and the kidneys. Clinical presentation of LCV varies from an acute self-limiting episode to recurrent or chronic forms.

In this article we report a case of a patient who developed painful skin lesions identified to be LCV almost one week after the use of Amoxicillin and Clavulanate potassium.

\section{Case Report}

A 22 year male presented to us with complain of fluid filled lesions over bilateral lower limbs since 9 days. The patient initially had red raised skin lesions which eventually became fluid filled, and these lesions initially localized to the dorsal aspect of right leg and over a period of 3 to 4 days spread to bilaterally extending upto the thigh, also involving the both forearms and hands. These lesions was associated with itching, burning sensation. There was H/o pain in large joints and pedal odema. There was no H/o upper respiratory tract infection, pain in abdomen, Hematemesis and hemoptosis. Patient gave H/o taking Amoxicillin and Clavulanate potassium and paracetamol for 3 day for fever following which the skin lesions occurred 7 days later. On General examination patient was afebrile, pulse $78 / \mathrm{min}$, BP $-110 / 70 \mathrm{mmHg}$, no signs of pallor, icterus, clubbing, cyanosis, lymphadenopathy. Patient had pedal odema and arthralgia. Systemic examination was within normal limits. On cutaneous examination there was multiple palpable purpura of varying sizes mainly distributed on both upper and lower limb. Few of them had vesiculo-bullous eruption predominantly present on both lower legs (Fig. 1). Few bulle were ruptured with serosanguinous discharge were present over bilateral lower limbs sparing the trunk and face. Oral, genital and anal mucosae were normal. Then we investigated the patient for complete blood count (CBC) revealed eosinophilia. Liver function test, Renal function test, Urine analysis and USG abdomen were normal. HbsAg, ANA, ASO titre and HIV test were negative. 
Clinically we thought the differential diagnosis for the patient was of Henoch Schonlein purpura because of the patient age, Leucocytoclastic vascultits secondary to drugs, Allergic contact dermatitis and Erythema Multiforme.

Then we did skin biopsy with $4 \mathrm{~mm}$ punch from ant. compartment of thigh showed palpable purpura clinically. Histopathology report revelaed that inflammatory pathology was predominantly confined to superficial dermis consisting of perivascualar infiltrate consisting of mainly neutrophils and few lymphocytes. Neuclear fragmentation and vascular wall damage was also seen suggestive of leucocytoclastic vasculitis (Fig. 2). The patient had taken paracetamol for his fever in the past with no adverse reactions. So paracetamol being the causation of his lcv was

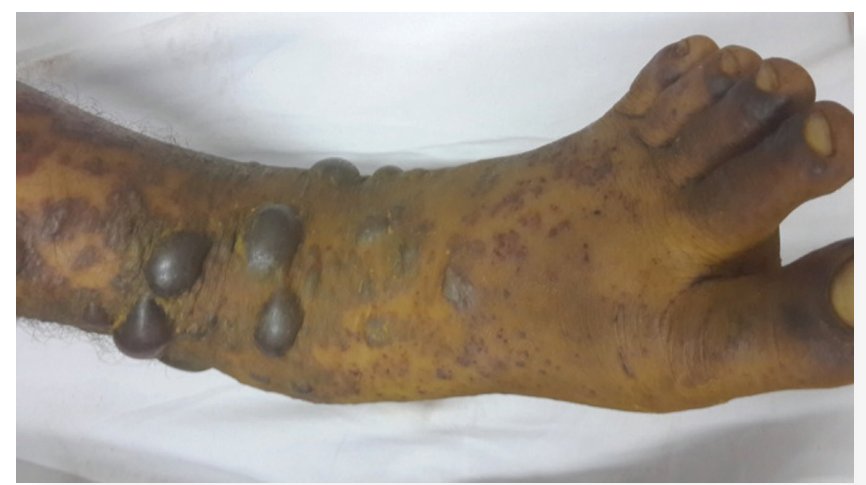

Figure 1. Multiple palpable purpura with vesiculobullous eruptions over the left lower leg. ruled out. On the basis of clinical \& histopathological findings confirm the diagnosis of Leucocytoclastic vasculitis secondary to Amoxicillin and Clavulanate potassium was made. The patient was treated with primarily removal of the offending drug, and elevation of the leg because LCV rash involves dependent areas. On systemically we treat him with I.V Dexamethasone, for ten days followed by oral prednisolone in tapering doses. Oral antibiotic (Azithromycin), topical corticosteroids were also given and patient was advised to follow up after one week. Patient showed signs of improvement as only mild erythema was seen after a week and post-inflammatory hyperpigmentation after a month.

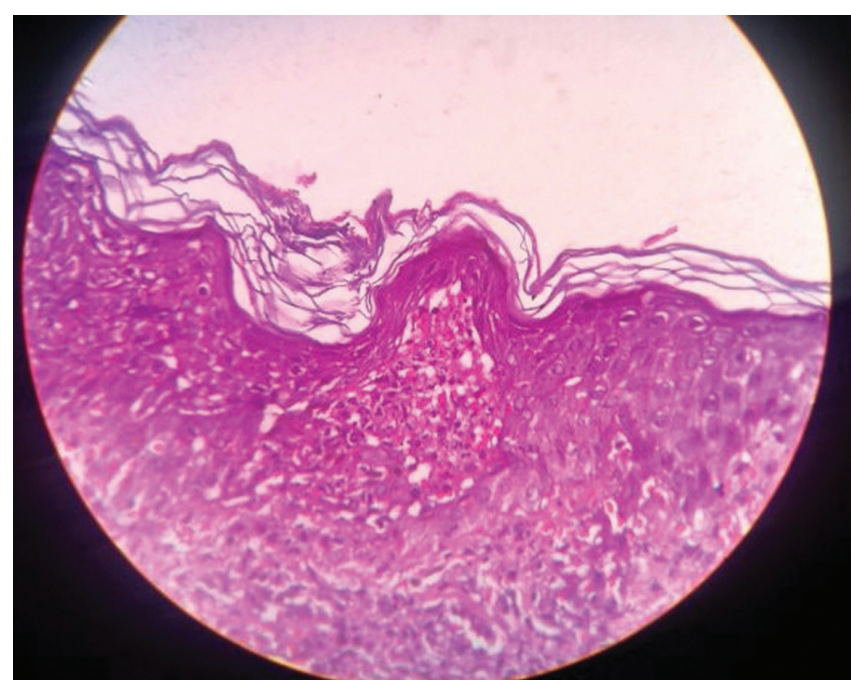

Figure 2. Histopathology showing epidermis and dermis with characterstic neuclear dust in dermis. (H\&E stain 40X)

\section{Discussion}

LCV is a small-vessel hypersensitivity vasculitis with a reported incidence rate of about 30 cases per million people per year [1]. LCV can occur at any age group and is thought to effect men and women in equal numbers but few studies suggest male predominance [2]. Multiple etiologic factors including drugs, infections, foods, autoimmune diseases, collagen vascular diseases and malignancies have been suggested to associate with LCV [3-6]. Though exact pathogenic mechanism of LCV remains to be elucidated, circulating immune complexes are believed to be involved in the pathogenesis of LCV [7].

LCV usually presents as a palpable purpuric rash associated with burning sensation or pain and is most commonly observed on the legs, but any surface may be involved. Rarely the presentation may include completely asymptomatic lesions, nodular lesions or ulcerations. Thorough history of recent infections, change in medications or food etc. along with a detailed physical examination to find etiologic trigger or an associated disorder should be performed. Identification and avoidance or treatment of the etiologic trigger may prevent recurrent episodes of LCV. Diagnosis of LCV is confirmed on histological examination of the sample obtained on biopsy of the affected area. Histologically, LCV demonstrates perivascular and vascular leucocytic infiltrates along with fibrinoid necrosis. Etiological triggers are usually identified with the temporal association. In our patient, palpable purpura start after Amoxicillin and Clavulanate potassium tablet intake of duration 3 to 4 days and its stop spreading after removal of drug. Considering patient had history of migraine and he had took paracetamol multiple times, chances paracetamol was involved in the pathogenesis of LCV were less likely. Furthermore Azithromycin and I.V. Dexamethasone was continued throughout the course of the treatment and rash resolved for 10 days. Then patint shifted to oral prednisolone in tapering doses with topical corticosteroids $\&$ antibactrials. Since Amoxicillin and Clavulanate potassium was the only new medicine to which the patient was recently exposed to, it was thought to be the etiologic trigger for $\mathrm{LCV}$ in this case. Further, the LCV rash improved after the discontinuation of the Amoxicillin and Clavulanate potassium confirming our hypothesis.

Treatment of LCV is identification and removal or treatment of the offending etiologic factor, and elevation of the leg and use of compression stocking if LCV rash involves dependent areas. Colchicine [8] and dapsone [9] have been shown to be useful in cases of LCV. Urticarial lesions can be managed with the antihistaminic medicines. 
Systemic steroids and other immunosuppressive agents [10] may be used in cases of deep organ involvement.

In conclusion, Clinicians need to be suspect of druginduced vasculitis to enable prompt diagnosis and treatment. Identification of potential etiological triggers in cases of LCV can prevent significant morbidity related with recurrences. Multiple antibiotics including Amoxicillin and Clavulanate potassium can act as a potential trigger for LCV which was very commonly used in daily practice.

\section{REFERENCES}

1. Garcia-Porrua C, Gonzalez-Gay MA. Comparative clinical and epidemiological study of hypersensitivity vasculitis versus HenochSchönlein purpura in adults. Semin Arthritis Rheum. 1999;28:40412.

2. Gonzalez-Gay MA, Garcia-Porrua C. Systemic vasculitis in adults in northwestern Spain, 1988-1997. Clinical and epidemiologic aspects. Medicine. 1999;78:292-308.

3. Sams WM. Hypersensitivity angiitis. J Invest Dermatol. 1989;93:78S-81S.
4. Dubost JJ, Souteyrand P, Sauvezie B. Drug-induced vasculitides. Baillieres Clin Rheumatol. 1991;5:119.

5. Solans-Laque R, Bosch-Gil JA, Perez-Bocanegra C, Selva-O Callaghan A, Simeon-Aznar CP, Vilardell-Tarres M. Paraneoplastic vasculitis in patients with solid tumors: report of 15 cases. J Rheumatol. 2008;35:294-304.

6. Fain O, Hamidou M, Cacoub P, Godeau B, Wechsler B, Paries $\mathrm{J}$, et al. Vasculitides associated with malignancies: analysis of sixty patients. Arthritis Rheum. 2007;57:1473-80.

7. Mackel SE, Jordon RE. Leukocytoclastic vasculitis. A cutaneous expression of immune complex disease. Arch Dermatol. 1982;118:296-301.

8. Sais G, Vidaller A, Jucgla A, Gallardo F, Peyri J. Colchicine in the treatment of cutaneous leukocytoclastic vasculitis. Results of a prospective, randomized controlled trial. Arch Dermatol. 1995;131:1399-402.

9. Wolf R, Tuzun B, Tuzun Y. Dapsone: unapproved uses or indications. Clin Dermatol. 2000;18:37-53.

10. Keogh KA, Ytterberg SR, Fervenza FC, Carlson KA, Schroeder DR, Specks U. Rituximab for refractory Wegener's granulomatosis: report of a prospective, open-label pilot trial. Am J Respir Crit Care Med. 2006;173:180-87.

\footnotetext{
Copyright by Snehal Balvant Lunge, et al. This is an open access article distributed under the terms of the Creative Commons Attribution License, which permits unrestricted use, distribution, and reproduction in any medium, provided the original author and source are credited.
} 